
\title{
3 Research Soure \\ The effectiveness of online metacognitive versus face-to-face counseling on anxiety and metaworry in women with a history of spontaneous miscarriage: A Randomized clinical trial
}

\section{Mina Ghiasi shaham Abadi}

Shahid Sadoughi University of Medical Sciences and Health Services

Tahmineh Farajkhoda ( $\sim$ farajkhoda_t@yahoo.com )

Shahid Sadoughi University of Medical Sciences and Health Services https://orcid.org/0000-00018856-6348

Hassan Zareei Mahmoodabadi

Yazd University

\section{Research article}

Keywords: Counseling, Metacognition, Stress, Anxiety, Concern, Abortion, on line, face to face, miscarriage

Posted Date: October 19th, 2020

DOI: https://doi.org/10.21203/rs.3.rs-81434/v1

License: (c) (1) This work is licensed under a Creative Commons Attribution 4.0 International License.

Read Full License 


\section{Abstract}

\section{Background}

Online and face-to-face counseling interventions can be performed on women with a history of miscarriage, which causes their anxiety and metaworry. The aim of this study was to compare effectiveness of metacognitive counseling methods, online and face-to-face, on anxiety and metaworry of women with miscarriage.

\section{Methods}

In this parallel randomized clinical trial, 40 women with a history of miscarriage, anxiety and metaworry were randomly assigned to two groups ( $n=20$ /each): group I receiving metacognitive counseling via online network and software, and group II (control) receiving face-to-face metacognitive counseling with same content and time, 90-minute sessions. Data were collected demographic form, Beck Anxiety Inventory, Wellz metaworry questionnaire and satisfaction scale. Primary outcomes included changes in the scores of anxiety, metaworry were measured in both groups in three times including at the base line, and at the end of week eight and twelve of the intervention initiation. Satisfaction with counseling method was assessed as secondary outcome at the end of week eight and twelve of the intervention beginning in both groups.

Results

In both groups, mean score of anxiety in 12th week was significantly different from before the intervention; difference was more significant in online group $(p=0.04)$. In both groups, the mean score of metaworry in 12th week had a statistically significant difference compared to the beginning of the study, and the decrease was again more significant in the online group $(p=0.03)$. Satisfaction with the counseling method had statistically significant difference between the two groups in week eight and twelve (respectively $p \approx 0.00$ ).

\section{Conclusions}

Metacognitive counseling both online and face-to-face improves anxiety and metaworry in women with miscarriage. Online counseling was more effective, satisfying, and longer compared with face-to-face counseling method, especially in corona virus 19 outbreak.

Trial registration: ISRCTN, IRCT20181120041707N1, Prospectively registered, Registered 23 May 2019, https://en.irct.ir/trial/35643/ IRCT20181120041707N1

\section{Background}

Miscarriage or spontaneous abortion is defined as the pregnancy loss or labor induction before the fetus is able to survive, independently[1, 2], the prevalence of which in Iran is 9.8 cases per 1000 pregnancies 
per year[3]. Stress, anxiety, and severe concern are the psychological consequences of miscarriage[4] Psychological symptoms of women with miscarriage are similar to those of mothers who have lost their babies [5]. Anxiety is an emotional state characterized by feeling of tension, anger, anxiety, fear, and increased activity of the autonomic system, thus leading to a physical-psychological response [6]. Metaworry means worry about worry. Whenever normal anxiety becomes a pathological concern, metaworry arises[7].

There are several treatments' methods for anxiety, including relaxation, logo therapy, medication, film therapy, the use of electric shock, and psychotherapy[8, 9]. Psychological counseling is one way to treat anxiety [8] and reduces the patient's fears and anxieties due to lack of awareness[10]. One of the counseling methods is metacognitive therapy, attempting to change metacognition, which unfavorably increases repetitive negative thoughts or common negative beliefs[11]. Metacognition denotes a multifaceted concept including knowledge (belief), processes, and strategies that evaluate, monitor, or control cognition [12]. The metacognitive therapies can impinge on the expression of some polymorphisms in the serotonin gene, which ultimately raise serotonin release [13].

Today, online methods of consulting in health services are emphasized compared to the traditional methods, the benefits of which include flexibility, elimination of unnecessary and costly traffic use to participate in the counseling courses, reduction of costs, and adjustment of the level of learning according to the individual conditions of the client[14]. Online method disadvantages include the need for internet literacy, lack of eye contact in counseling, thus reducing the effectiveness of on-therapy relationship, the possibility of misunderstanding and lack of internet access $[15,16]$. Internet-based interventions have been used which have shown to be more acceptable than face-to-face counseling[17, 18]. However, in another study, face-to-face counseling has proved to be more accepted by participants than the online type[19].

Recent report has indicated that $92 \%$ of women with abortion seek post-miscarriage care, out of which only one-third receive this type of care; additionally, many patients express their anger and dissatisfaction as for receiving insufficient psychological support after miscarriage. To put it another way, more attention is paid to the physical complaints of women with miscarriage than to their psychological needs [5]. In one study has shown that lack of pre-miscarriage counseling can lead to post-miscarriage psychological problems[20]. Considering corona virus outbreak, the importance of distance online counseling to help who needed these services is crucial, although the online method enjoys lack of embarrassment on the part of the patient, regards privacy, and is independent of time and place, due to the limited number of online counseling studies in Iran, it was necessary to compare the effectiveness, sustainability, and satisfaction of metacognitive counseling through online and face-to-face methods. The study questions were which of two counseling metacognitive methods online and face-to-face had more effectiveness on improvement of anxiety and metaworry, and associated with more satisfaction. The aim of this study was to compare the effectiveness of metacognitive counseling via online and face-to-face methods on the anxiety and metaworry of women with a history of spontaneous miscarriage. 


\section{Methods}

\section{Study design}

In this parallel Randomized clinical trial (randomly allocation and concealment, presence of face to face metacognitive group as control group, IRCT registration Code: IRCT20181120041707N1).

\section{Participants and randomization}

80 women with a history of spontaneous abortion referred to Imam Jafar Sadegh hospital, Meybod, Iran were assessed for study eligibility criteria. All participants were eligible according to the inclusion criteria consisted of Iranian ethnicity, being married, history of spontaneous abortion, wanted pregnancy, having an Android or IOS mobile phone, willingness to participate in counseling sessions, having interest to perform the relevant tasks (attending all or at least 6 sessions, and performing more than $75 \%$ of assignments at the discretion of the counselor), having mild or moderate anxiety and a metaworry score $<10$. Exclusion criteria were the history of alcohol, tobacco, or medications use such as antidepressants according to the individual herself report, presence of systemic disorders, gynecologic or mental diseases based on women self administration, simultaneous participation in a similar study, presence of a problem that superimposed sadness, anxiety, and depression, such as the death of the loved ones, etc. in the previous two months, as well as pregnancy.

Due to lack of eligibility criteria in some women and high probability of women withdrawal in each group during the study stages, 80 women with a history of spontaneous abortion referred to Imam Jafar Sadegh hospital, Meybod, Iran were assessed for eligibility criteria in 26.5.2019. Each of the women was then given a code based on a simple random computerized table number that generated by a statistics specialist. First author enrolled participants, and assigned participants to interventions under supervision of second author. Each code was randomly assigned to one of the online counseling or face-to-face counseling (control) groups until the samples were completed in each group ( $n=20 /$ each). The final samples were called; the purpose and method of the study were explained to them. Women that did not wish to attend the study (six women), did not meet inclusion criteria (34 women) or for other reasons (none of women) were excluded from the study and replaced with another one (Figure 1). After random allocation of 40 eligible women into two online consulting group $(n=20)$ and face-to-face counseling group (as control group $n=20$ ), women in each group were randomly divided into two groups (two sub groups) of ten women ( $B$ and $A$ ) using the coin toss method again. Forty eligible women signed an informed consent form to participate in counseling sessions. Women were aware from their intervention because of counseling intervention nature, therefore blindness was not applicable.

\section{Sample size estimation}

The sample size was estimated to be 40 (20 in each group) based on previous studies [21, 22] by considering $a=0.05, \beta=90 \%$, and $\sigma=3.5$, and to achieve a significant difference of at least 5 points in the mean scores of the anxiety questionnaire as well as considering $10 \%$ attrition probability. We used the 
statistical formula $n=2(z 1-a / 2+z 1-b)^{2} s^{2} /(\mu 1-\mu 2)^{2}$ for sample size determination. In this study 20 women (in two groups of 10 ) were receiving metacognitive counseling through online consulting and 20 others (in two groups of 10 ) receiving face-to-face counseling.

\section{Data collection instruments (4 tolls)}

Demographic Questionnaire: It included age, gravidity, level of education, occupation, number of miscarriages, gestational age at the time of miscarriage, the time interval since the last abortion, history of anxiety, and previous efforts to reduce anxiety.

Beck Anxiety Inventory: A 21-item four-choice question is scored on a four-part spectrum from zero to three points [23]. The test has a content validity, stability $=0.838$; and internal consistency (Cronbach's alpha) is 0.92 [24].

Metaworry Wellz Questionnaire: This is a 7-item self-reported scale designed to assess the risk aspect of metaworry and the frequency and extent of belief in anxiety. To assess the frequency of metaworry beliefs, the responses on this scale are based on a four-point Likert scale (1-never to 4-always) with a minimum score of 7 and a maximum of 28 , and to measure a belief in metaworry. It is calculated based on a 100-degree continuum (0-"I don't believe in this at all" to "I fully believe in this"). The correlation coefficient of the metaworry questionnaire is between 0.72 and 0.87 [25] In Sharifi Saki's study, the internal consistency coefficient of this scale turned out to be 0.81 [26] .

Satisfaction with the counseling method scale: This variable investigated at the end of the researchermade scale using relevant references in the form of score scales between 1 and 10 in seven questions at weeks eight and twelve after the intervention that were responded by women in both groups [27, 28].

\section{Interventions}

The online and face-to-face intervention was carried out under the group counseling protocol during eight 90-minute counseling sessions (Table 1 ) based on related other studies [29,30] by first author who had studied counseling and obtained a certificate of ability to perform a metacognitive course under supervision of first and second author. The content of the online counseling sessions was provided in the form of multimedia for two online groups $(n=20)$ (randomly divided into two 10 women) at a specific time and day in week according to the agreement reached with the participants through on line software and Whats App software. At the beginning of each session, a summary of the contents of the previous session was reviewed, and while providing counseling materials online, they were asked to participate in online counseling discussions and express their concerns as well as their progress and report to the counselor with online chat. In order to encourage them more in the counseling topics, appropriate questions were prepared based on the principles of metacognitive counseling, that were all discussed in the group. At the end of each session, the important points were repeated and summarized. Online 
assignments accomplished by each individual were also reviewed by the counselor so that each person's progress was reported. It was also possible to ask the counselor questions online and in person. In case the person was absent from the online session, she would be asked via SMS to join the group. In case of internet disconnection, the meeting would be held online again with the agreement of the members.

For the control group ( $n=20)$ (face-to-face counseling group randomly was divided into two 10 women groups), however, face-to-face counseling was performed for both two face to face groups once day in week with the agreement on exact time by the women participating in the study at Imam Jafar Sadegh hospital, Meybod, Yazd for providing appropriate space and facilities for counseling sessions. This group, as in the online group, was involved in a beginning session, an invitation outline to actively participate in the group counseling session, and the possibility of asking private questions after the group meeting in person. Both of two groups' online and face to face groups, received same counseling content in same counseling length time by the same counselor.

Table 1. Content of metacognitive therapy sessions based on related other studies $[29,30]$ 


\begin{tabular}{|c|c|c|c|}
\hline Homework assessment & Aims & Contents & Sessions \\
\hline \multirow[t]{2}{*}{$\begin{array}{l}\text { In each session, a number of } \\
\text { participants were asked to do the } \\
\text { assignment at the presence of } \\
\text { the researcher. In online method, } \\
\text { participants were also asked to } \\
\text { describe the assignments. Each } \\
\text { evaluation was regarded as } \\
\text { acceptable or unacceptable, and } \\
\text { required feedback was presented. }\end{array}$} & $\begin{array}{l}\text { Provision of a summary of } \\
\text { the miscarriage definition, its } \\
\text { causes and treatment methods, } \\
\text { Evaluation of symptoms and } \\
\text { introduction of emotional } \\
\text { abnormality and attention bias, } \\
\text { segregation of normal and } \\
\text { problematic social anxiety for } \\
\text { individuals, } \\
\text { Identification of the need for } \\
\text { treatment }\end{array}$ & $\begin{array}{l}\text { Welcome } \\
\text {. explain the } \\
\text { venue, the } \\
\text { number of } \\
\text { sessions, the } \\
\text { length of the } \\
\text { course and the } \\
\text { duration of each } \\
\text { session, and the } \\
\text { group's rules and } \\
\text { regulations, } \\
\text { Introducing } \\
\text { the group } \\
\text { members to } \\
\text { each other, } \\
\text { Providing a } \\
\text { summary of the } \\
\text { treatment } \\
\text { method and the } \\
\text { purpose of the } \\
\text { sessions }\end{array}$ & 1 \\
\hline & $\begin{array}{l}\text { Presentation of the logic of } \\
\text { metacognitive therapy for } \\
\text { psychological disorders and } \\
\text { promotion of normal states, } \\
\text { Study of the symptoms of } \\
\text { emotional abnormality and } \\
\text { attention disorders in } \\
\text { individuals, } \\
\text { S Study of the possible } \\
\text { effective causes in the etiology } \\
\text { of emotional abnormality and } \\
\text { attention disorders, } \\
\text { Review of various treatment } \\
\text { methods for emotional distress } \\
\text { and attention disorders, } \\
\\
\text { of Explanations about the logic } \\
\text { of metacognitive therapy for } \\
\text { emotional abnormality and } \\
\text { attention disorders, } \\
\text { Medical information about } \\
\text { miscarriage and its physical } \\
\text { side effects to reduce anxiety } \\
\text { and fear caused by lack of } \\
\text { awareness, as well as } \\
\text { information provision as to } \\
\text { miscarriage being also a kind } \\
\text { of loss or sorrow and therefore }\end{array}$ & $\begin{array}{l}\text { Expressing the } \\
\text { summary the } \\
\text { content of the } \\
\text { previous session } \\
\text { with the help of } \\
\text { the members, } \\
\text { Providing } \\
\text { homework and } \\
\text { emphasis on } \\
\text { homework, } \\
\text {. Receiving } \\
\text { feedback }\end{array}$ & 2 \\
\hline
\end{tabular}


can lead to similar symptoms of grief

Assessing and identifying
the positive and negative
metacognitive beliefs about
miscarriage in individuals and
analyzing the advantages and
disadvantages of these beliefs,
- Asking questions about
patients' concerns and
ambiguities around
miscarriage and resolving them
as far as possible

- Rreceiving feedback from the previous session,

- Reviewing the exercises and homework of the previous session,

- Teaching and practicing metacognitive techniques,

- Presenting homework

\section{- Identifying patients' metacognitive control strategies,}

- Analyzing the advantages and disadvantages of metacognitive control strategies used,

\section{- Replacing more useful metacognitive control strategies instead of worrying about miscarriage}

\section{- Receiving feedback from the previous session,}

Discussing
homework,

- Teaching and exercising, presenting homework,

\section{- Receiving feedback}
- Dealing with metacognitive strategies and inefficient ideas (patients learn to deal with their thoughts about miscarriage as a 'cloud' in their minds in case the thoughts do not need to be processed),

- Challenging with negative metacognitive beliefs about the dangers of miscarriage

\section{- Receiving feedback from the previous session,}

\section{- Discussing} homework,

- Teaching and exercising, Presenting
homework,

- Receiving feedback

- Familiarizing patients with two strategies of anxiety and mental rumination as ineffective coping strategies for
- Receiving feedback from the previous session, 
managing anxiety about miscarriage,

- Analyzing advantages and disadvantages of anxiety and mental rumination about miscarriage,

- Analyzing the process of suppressing thoughts as an inefficient process (white tiger) and familiarizing them with the consequences of conflict with symptoms

- Teaching how to delay worrying about the challenges of positive metacognitive beliefs about anxiety induced by abortion

\section{- Familiarizing patients with} cognitive attention signals in the persistence of mental disorders,

- Providing them with attention training technique and teaching them this as a supporting plan so as not to be worried about miscarriage
- discussing homework,

- Teaching and exercising, presenting homework,

- Receiving feedback

Receiving
feedback from
the previous
session,

- Discussing homework,

- Teaching and exercising, presenting homework,

- Receiving feedback

- Situational attention
refocusing as an effective
metacognitive strategy and
preparing members for closing
sessions
- Identifying barriers to
methods application, cause
seeking and eliminating it and
subsequently concluding
- Preventing relapse
- Discussing current mental
state of the patients and their
concerns about miscarriage

- Receiving feedback from treatment sessions and its impact on group members,

- Reviewing assignments and answering questions and problems,

- Practicing the techniques learned in previous sessions with the participation of members,

- Expressing the need to use the 
learned

techniques to

reduce the

symptoms of the

disease and

increasing

overall

improvement,

- Answering the

questions posed

\section{Ethic}

The study protocol was approved by of the ethics committee Shahid Sadoughi University of Medical Science, Yazd, Iran (Code: IR.SSU.REC.1397.091) and registered in Iranian Registry of Clinical Trials (IRCT Code: IRCT 20181120041707N1). Written informed consent was obtained from each women participating in the study.

\section{Outcomes}

\section{Primary outcomes}

The primary outcomes of the study were the changes in the mean score of anxiety, metaworry that measured three times including at the base line and at the end of the eighth and twelfth weeks of the intervention in the two groups. These outcomes were measured in face to face metacognitive counseling group via face to face interview by Beck Anxiety Inventory, Metaworry Wellz Questionnaire at the baseline and at the end of eighth and twelfth weeks (fallow up) of intervention. In online metacognitive counseling group the same online questionnaires were sent to each women of the online metacognitive counseling group at the same times as face to face metacognitive counseling group.

\section{Secondary outcomes}

The secondary outcome of the study was measurement of satisfaction with the counseling method that was assessed at the end of the eighth and twelfth weeks of the intervention in the two groups. It was assessed at weeks eight and twelve after the intervention via face to face (for face to face metacognitive counseling group) and online (for online metacognitive counseling group) in both groups.

\section{Statistical analysis}

Statistical analysis was done using Statistical Package for the Social Sciences, frequency, percentage, mean, and standard deviation as well as, and Smirnov's normality, Chi-square, Student's $t$ test, and Repeated measure. For both primary and secondary outcomes Student's $t$ test, and Repeated measure were used. P-value $<0.05$ were considered significant.

\section{Results}




\section{Participant flow and numbers analyzed}

The data of 40 women in two on line group $(n=20)$ and face to face group participating in the study were analyzed after ending the trial in $12^{\text {th }}$ week after initiation of intervention when the study completed based on figure 1 .

\section{Participant characteristics}

Kolmogorov Smirnov's normality test was done. Most participants in both groups being housewives, gravida II, had a diploma's degree or higher of education level. The mean age of the participants was $27.27 \pm 6.06$ years with a minimum age of 18 and a maximum of 39 years. The groups did not have statistically significant differences in terms of demographic characteristics (Table 2).

Table 2. Comparison of demographic characteristics between two study groups ( $n=20 /$ each) 


\begin{tabular}{|c|c|c|c|c|c|c|}
\hline \multirow{2}{*}{$\begin{array}{l}\text { Group } \\
\text { Variable }\end{array}$} & & \multicolumn{2}{|c|}{$\begin{array}{l}\text { Face to face consultation } \\
\text { (control) }\end{array}$} & \multicolumn{2}{|c|}{ Online counseling } & \multirow[t]{2}{*}{$\begin{array}{l}\mathrm{p}- \\
\text { value }\end{array}$} \\
\hline & & Frrequency & Percent & Frrequency & Percent & \\
\hline \multirow[t]{3}{*}{ Job } & Free & 3 & 15 & 7 & 35 & \multirow[t]{3}{*}{$0 / 33$} \\
\hline & Governmental & 1 & 5 & 1 & 5 & \\
\hline & Housewife & 16 & 80 & 12 & 60 & \\
\hline \multirow{4}{*}{$\begin{array}{l}\text { The number of } \\
\text { pregnancy }\end{array}$} & First & 0 & 0 & 1 & 5 & \multirow[t]{4}{*}{0.20} \\
\hline & Second & 12 & 60 & 16 & 80 & \\
\hline & Third & 6 & 30 & 3 & 15 & \\
\hline & $\begin{array}{l}\text { Fourth and } \\
\text { more }\end{array}$ & 2 & 10 & 0 & 0 & \\
\hline \multirow[t]{4}{*}{ Level of Education } & Cycle & 1 & 5 & 3 & 15 & \multirow[t]{4}{*}{0.08} \\
\hline & & 15 & 75 & 8 & 40 & \\
\hline & Diploma & & & & & \\
\hline & University & 4 & 20 & 9 & 45 & \\
\hline \multirow{3}{*}{$\begin{array}{l}\text { Number of } \\
\text { abortions }\end{array}$} & One & 12 & 60 & 16 & 80 & \multirow[t]{3}{*}{0.03} \\
\hline & Two & 7 & 35 & 4 & 20 & \\
\hline & $\begin{array}{l}\text { Three and } \\
\text { more }\end{array}$ & 1 & 5 & 0 & 0 & \\
\hline \multirow[t]{2}{*}{ History of anxiety } & Yes & 7 & 35 & 8 & 40 & \multirow[t]{2}{*}{0.74} \\
\hline & No & 13 & 65 & 12 & 60 & \\
\hline
\end{tabular}

* Chi-square test

** Indepenent Smples $t$ Test

\section{Primary outcomes}

Table 3. Comparison mean anxiety score and its changes in before and after intervention in two groups $(n=20 /$ each $)$ 


\begin{tabular}{|c|c|c|c|c|}
\hline Groups & $\begin{array}{l}\text { Face to face } \\
\text { consultation }\end{array}$ & $\begin{array}{l}\text { online } \\
\text { consultation }\end{array}$ & $F$ & $\begin{array}{l}\text { Independent } \\
\text { Samples T } \\
\text { Test }{ }^{\star \star}\end{array}$ \\
\hline Variable & $\begin{array}{l}\text { ( control } \\
\mathrm{n}=20)\end{array}$ & $(n=20)$ & & p-value \\
\hline $\begin{array}{l}\text { Base line } \\
\text { (mean } \\
\text { standard deviation) } \pm\end{array}$ & $4 / 93 \pm 22 / 35$ & $\begin{array}{l}5 / 67 \pm \\
22 / 15\end{array}$ & $0 / 33$ & $0 / 56$ \\
\hline $\begin{array}{l}8 \text { weeks after the intervention (mean } \\
\text { standard deviation) } \pm\end{array}$ & $6 / 25 \pm 18 / 45$ & $5 / 03 \pm 17 / 00$ & $0 / 97$ & $0 / 33$ \\
\hline $\begin{array}{l}\text { Fallow up } 12 \text { weeks after the beginning of } \\
\text { intervention (mean } \pm \text { standard deviation) }\end{array}$ & $5 / 91 \pm 18 / 25$ & $\begin{array}{l}3 / 59 \pm \\
13 / 75\end{array}$ & $4 / 38$ & $0 / 04$ \\
\hline $\mathbf{F}$ & $3 / 255$ & $15 / 260$ & & \\
\hline$p$-value & $0 / 04$ & $\approx 0 / 00$ & & \\
\hline Repeated measure * & & & & \\
\hline
\end{tabular}

\section{*Repeated measure \\ **Independent Samples T Test}

The mean score of anxiety before the intervention $(p=0.56)$ and 8 weeks after the intervention $(p=0.33)$ did not differ significantly between the study groups. However, 12 weeks after the intervention, the mean changes of anxiety score were significantly different between the two groups $(p=0.04)$, so that the effectiveness of online counseling were higher than that of face-to-face method. Intergroup comparisons showed the mean anxiety score decreasing significantly in 8 and 12 weeks after the intervention in the online counseling group $(p \approx 0.00)$ compared with that of before. Further, in the face-to-face counseling group, the anxiety level decreased in 8 and 12 weeks after the intervention which was significantly lower than that of before the intervention $(p=0.04)$, but the mean anxiety score in the online counseling group proved to be lower (Table 3).

Table 4: Comparison mean of metaworry score in before and after intervention in two groups 


\begin{tabular}{|c|c|c|c|c|}
\hline Groups & $\begin{array}{l}\text { Face to face } \\
\text { consultation }\end{array}$ & $\begin{array}{l}\text { online } \\
\text { consultation }\end{array}$ & $F$ & $\begin{array}{l}\text { Independent } \\
\text { Samples } \\
\text { Test }{ }^{\star \star}\end{array}$ \\
\hline Variable & $\begin{array}{l}\text { ( control } \\
\mathrm{n}=20)\end{array}$ & $(n=20)$ & & p-value \\
\hline $\begin{array}{l}\text { Base line } \\
\text { (mean } \pm \text { standard deviation) }\end{array}$ & $3 / 47 \pm 18 / 50$ & $\begin{array}{l}2 / 70 \pm \\
17 / 15\end{array}$ & $0 / 850$ & $0 / 36$ \\
\hline $\begin{array}{l}8 \text { weeks after the intervention (mean } \\
\text { standard deviation) } \pm\end{array}$ & $4 / 07 \pm 15 / 80$ & $\begin{array}{l}3 / 16 \pm \\
14 / 40\end{array}$ & $0 / 961$ & $0 / 33$ \\
\hline $\begin{array}{l}\text { Fallow up } 12 \text { weeks after the begining of } \\
\text { intervention (mean } \pm \text { standard deviation) }\end{array}$ & $4 / 06 \pm 15 / 70$ & $2 / 59 \pm 11 / 90$ & $4 / 883$ & $0 / 03$ \\
\hline$F$ & $3 / 351$ & $17 / 196$ & & \\
\hline$p$-value & $0 / 04$ & $\approx 0 / 00$ & & \\
\hline Repeated measure* & & & & \\
\hline
\end{tabular}

*Repeated measure

**Independent Samples T Test

The mean score of metaworry before intervention $(p=0.36)$ and 8 weeks after intervention $(p=0.33)$ did not differ significantly between the studied groups, but the mean change in 12 weeks after the intervention turned out to be significantly different between the two groups $(p=0.03)$; so that the effectiveness of online counseling showed higher than that of face-to-face counseling. Intergroup comparisons also revealed that in the online counseling group, the mean score of metaworry diminished significantly in the 8and 12 weeks after the intervention $(p \approx 0.00)$. In the face-to-face counseling group, the metaworry rate also decreased in 8 and 12 weeks after the intervention which stood significantly lower than that of before the intervention $(p=0.04)$; this rate, however, was lower compared to the online counseling group (Table 4).

Table 5. Comparison mean scores of belief about worry in before and after intervention in two groups 


\begin{tabular}{|c|c|c|c|c|}
\hline Groups & $\begin{array}{l}\text { Face to face } \\
\text { consultation }\end{array}$ & $\begin{array}{l}\text { online } \\
\text { consultation }\end{array}$ & $F$ & $\begin{array}{l}\text { Independent } \\
\text { Samples } \\
\text { Test } \star \star\end{array}$ \\
\hline Variable & $\begin{array}{l}\text { ( control } \\
\mathrm{n}=20)\end{array}$ & $(n=20)$ & & p-value \\
\hline $\begin{array}{l}\text { Base line } \\
\text { (mean } \\
\text { standard deviation) } \pm\end{array}$ & $8 / 85 \pm 86 / 05$ & $8 / 87 \pm 85 / 50$ & $0 / 002$ & $0 / 96$ \\
\hline $\begin{array}{l}8 \text { weeks after the intervention (mean } \\
\text { standard deviation) } \pm\end{array}$ & $11 / 36 \pm 78 / 50$ & $12 / 18 \pm 73 / 00$ & $0 / 167$ & $0 / 68$ \\
\hline $\begin{array}{l}\text { Fallow up } 12 \text { weeks after the beginning of } \\
\text { intervention (mean } \pm \text { standard deviation) }\end{array}$ & $9 / 27 \pm 78 / 45$ & $14 / 60 \pm 66 / 50$ & $6 / 284$ & $0 / 01$ \\
\hline $\mathbf{F}$ & $3 / 910$ & $12 / 701$ & & \\
\hline$p$-value & $0 / 02$ & $\approx 0 / 00$ & & \\
\hline Repeated measure* & & & & \\
\hline
\end{tabular}

*Repeated measure

**Independent Samples T Test

The mean score of belief in concerns before intervention $(p=0.96)$ and 8 weeks after intervention $(p=$ 0.68 ) had no significant difference between the studied groups, but 12 weeks after the intervention, the mean changes appeared to be significantly different between the two groups $(p=0.01)$; the effectiveness of online counseling was, however, higher than that of face-to-face method. Intergroup comparisons demonstrated the mean score of belief in concerns significantly decreased in the 8 and 12 weeks after the intervention in the online counseling group $(p \approx 0.00)$. The mean of belief in concerns as for face-toface group also significantly reduced in 8 and 12 weeks after the intervention $(p=0.02)$, but this was lower than the online counseling group (Table 5).

\section{Secondary outcomes}

Table 6. Comparison of total satisfaction score in $8^{\text {th }}$ and $12^{\text {th }}$ weeks after intervention in two groups 


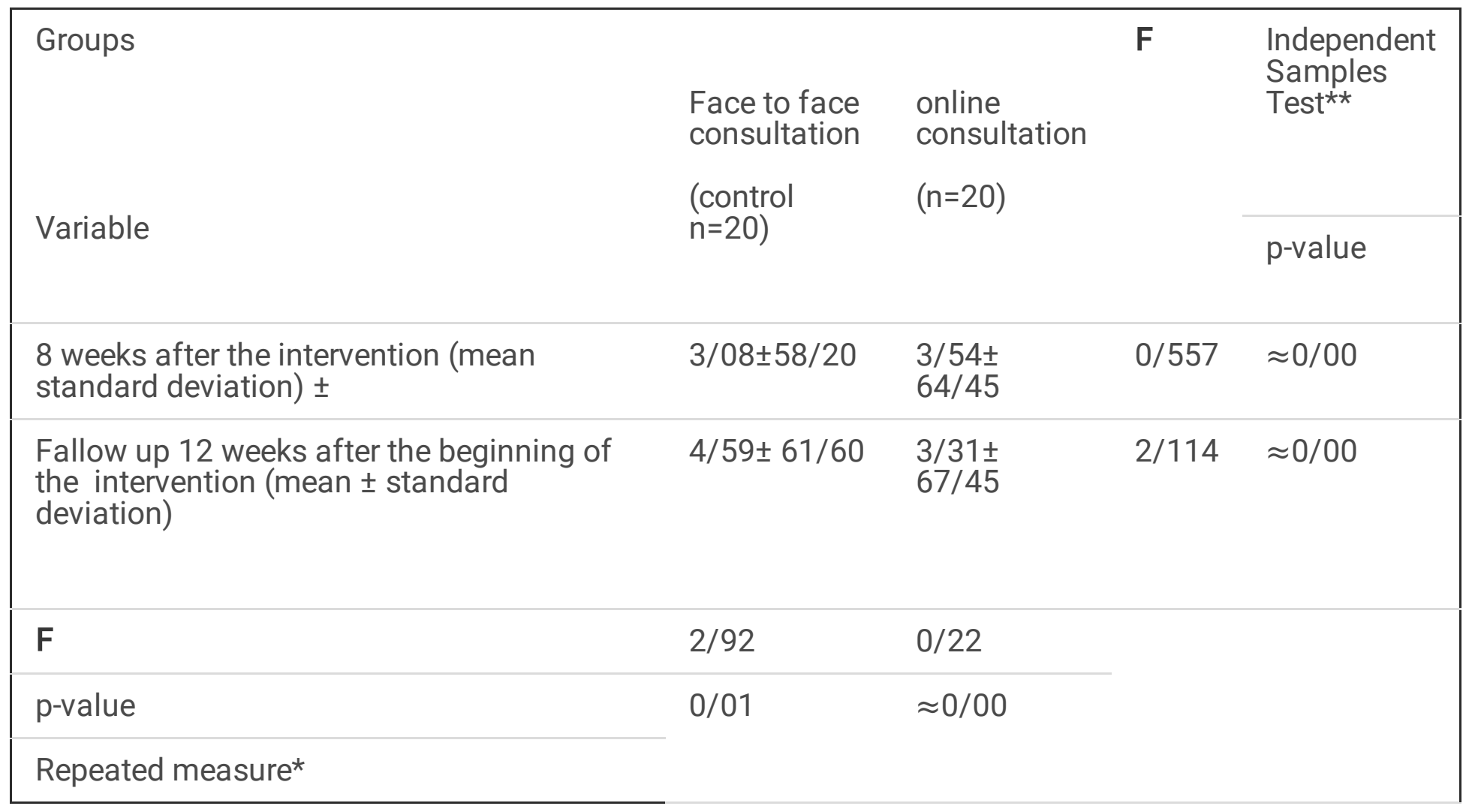

*Repeated measure

**Independent Samples T Test

The overall score of satisfaction from the online counseling method in $8^{\text {th }}$ and $12^{\text {th }}$ weeks after the intervention was significantly higher compared to that of face-to-face method $(p \approx 0.00)$. In addition, the overall score of satisfaction in week 12 compared to week 8 in the online counseling group $(p \approx 0.00)$ and face-to-face $(p=0.01)$ increased significantly (Table 6$)$.

\section{Discussion}

In this study, the effectiveness of online and face-to-face metacognitive counseling on anxiety and metaworry in women with a history of miscarriage was compared. Our results demonstrated the significant decrease in the mean score of anxiety and metaworry in both groups at 8th and 12th weeks following the intervention; this, however, proved more significant in the online group. Jlala and co-workers conducted a study to investigate the effect of preoperative multimedia training on preoperative anxiety in patients undergoing local anesthesia. Their results revealed that education through multimedia reduced the anxiety of these patients [31]. Kresting and colleagues, in 2013, showed that short internet-based interventions for 5 weeks significantly reducing post-traumatic stress symptoms, prolonged grief, depression, and anxiety[32], which is consistent with the results of the present study. One of the main reasons for the positive effect of online counseling method is the new and exciting visual and auditory nature and simulations that by knowing that the setting is online, the patient attempts to adapt to it, establish a constructive interaction, and eliminate the limitations of the real world. 
Olthuis and others concluded that cognitive-behavioral therapy through internet would fail to affect the patients with post-traumatic stress disorders, anxiety, and phobias[33], thus being inconsistent with the results of ours. Perhaps the justification for this discrepancy can be attributed to different geographical settings of the two studies and the way the intervention was conducted, as the two studies were conducted in two countries with two varying educational systems, or maybe the difference in the perspective of the participants, the training technique used, and duration of using these techniques, is the reason. Our results showed that in the face-to-face counseling group, the level of anxiety and metaworry decreases significantly after the intervention in the eighth and twelfth weeks. In line with these results, Delaram and Soltanpour conducted a study in 2012 to identify the effect of counseling in the third trimester of pregnancy on the anxiety of women on gravida 1 at the onset of labor. The results demonstrated that counseling with these women, not having a history of hospitalization and a known mental illness in the third trimester of pregnancy, reduces their anxiety at the onset of their labor[34]. In a study by Akhteh and co-workers, the effectiveness of cognitive-behavioral training in stress management by face-to-face counseling method reduced anxiety and metaworry in women with recurrent miscarriages[35]. Considering the psychological aspects can follow their better and more rapid treatment. Compared with fertile and healthy women, determining the emotional problems prevalent among infertile women who have experienced recurrent abortion and providing them with counseling services parallel with medical facilities appears to be regarded as crucial. In addition, providing required training to these women using related training workshops, training packages, as well as presenting media-based information to every person in the society can remarkably help reducing these patients' problems, thus being consonant with the results of ours[35].

It can be said that in face-to-face counseling, the counselor can benefit from communication skills and its possible positive effects and improve the awareness of the person being trained. On the other hand, the training provided to these people can be effective in this promotion.

Comparison of the mean anxiety and metaworry scores in the two online and face-to-face counseling groups before the intervention and the end of eighth and twelfth weeks exhibited no significant difference between the mean score of these variables before the intervention and 8 weeks after the intervention. However, 12 weeks after the intervention, anxiety and metaworry mean scores were significantly different between the two groups. So that, the effectiveness of online counseling turned out to be more significant than face-to-face procedure. In line with the results of the present study, Saleh Moghadam and colleagues showed that, the educational films were able to significantly reduce preoperative anxiety in patients who were candidates for open-heart surgery compared to face-to-face and pamphlet training methods[36]. It is because information is easily passed on to patients through instructional and multimedia videos; therefore, for the educational film it is not far-fetched to act more effective in reducing pre-operative anxiety compared with the intervention group. In addition, Carlbring and others in 2018 conducted a meta-analysis study with the aim of comparing two methods of internet-based and face-to-face cognitivebehavioral therapy for the treatment of mental and physical disorders. They studied 2078 articles and finally concluded that there was no significant difference between the two methods [37]. Our results proved to be consistent with the results of this study. 
Furthermore, the results of the present study illustrated the mean score of anxiety and metaworry not differing significantly between the studied groups before the intervention and 8 weeks afterwards; however, it shows that metacognitive counseling method is a good way to reduce the variables in both groups. Moreover, although there was no significant difference between anxiety and metaworry scores by week 8 compared to that of before the intervention, this could differentiate between the three time periods for the variables mentioned and trigger them to diminish significantly. Additionally, intragroup comparison of the results demonstrated a gradual reduction in the mean score of anxiety before the intervention and weeks 8 and 12 after the intervention in both groups; although statistically the difference was significant in both groups, the online counseling group had a greater reduction than the face-to-face one. Therefore, because the counseling method has exerted its desired effects on reducing anxiety and metaworry, and this positive effect has occurred in both groups, no statistically significant difference has been observed between the two groups at the end of week 8. Comparing the mean score of anxiety and metaworry between two groups at the end of 12th week indicated the changes in the mean scores being significantly different between the two groups thus revealing the effectiveness of online procedure being more evident compared to face-to-face counseling. The reason for this is likely persisting on online learning that occurs with its greater impact on memory or as a more attractive way for presenting educational content.

Comparison of mean satisfaction scores of counseling method at the end of the eighth and twelfth weeks showed that in both groups, satisfaction with the counseling method was significant, so that the level of online counseling satisfaction was higher than face-to-face counseling. Our results also showed that the intervention performed significantly increased the overall satisfaction score in 12th week compared to 8th week in the online and face-to-face counseling groups. Moreover, a study by Rufinigo and co-workers (2009) revealed that film-based training could reduce anxiety and increase patient satisfaction[38]. In addition, Ghalibaf and colleagues (2015) reported that $93.3 \%$ of respondents being very satisfied with online counseling[39]; this is also consistent with the results of ours. In justifying these findings, it can be maintained that metacognitive counseling through the internet and online space provides the therapist a high possibility and flexibility in terms of location and time, so could be replaced the need to meet and solve the problem in face to face methed. The ease of treatment from any place and time can potentially be addressed in several ways including financial phase, time, and energy. Online counseling, contrary to face-to-face method, can extend the therapy relationship between therapist and counselor and protect clients from possible inflictions resulting from therapeutic relationship disconnections. All of these factors increase the client's satisfaction compared with face-to-face counseling[40, 41].

As a result, it can be concluded that metacognitive counseling has been effective on anxiety and metaworry for the reason that an individual considers the need to worry as a kind of coping strategy; in other words, she fails to come up with breaking the chain of anxiety and thus regards worry as a factor in avoiding failure in the adaptation process[35]. The reason why both anxiety and metaworry decreased in this study is that in infertile women with frequent miscarriages, the factor for inducing anxiety and subsequent metaworry is highly evident [26] Metaworry is, in fact, the result of anxiety and stress so that 
by lowering the level of anxiety, it is possible to control metaworry as well [42]People who acquire the coping skills needed to control anxiety bear the potential to control their anxiety and worrying thoughts; as a result, stress, anxiety, and metaworry are continually reduced. The ineffective attitudes of women with recurrent miscarriages in relation to infertility and miscarriage play an important role in creating a negative view of oneself [43] Given the fact that metacognitive counseling mechanism helps people identify situations that cause anxiety and stress, gain a better understanding of them, identify their strengths and weaknesses, and then deal with coping strategies, it seems that metacognition is a good psychological technique for women with miscarriages [11].

The reason for the effectiveness, continuity, and satisfaction of the metacognitive online counseling method in the present study can likely be that online counseling is a new form of distance counseling emerged with the development of information and communication technology. Distinctive features of the online counseling method include the ease of transmitting information and its attractive and exciting visual and auditory nature, which, to some extent, removes the limitations of the real world. On the other hand, cost effectiveness is considered as one of the important advantages of remote counseling programs $[44,45]$. As the concluding remarks, the researcher believes people who have higher experience in dealing with the world of internet and virtual communications can better appreciate this treatment method. Today, onlining ( or the presence in the online space) in the daily lives of most Iranian women is of paramount importance; for this reason, online counseling can prove to be more effective and satisfying than face-to-face techniques due to its special benefits and attractiveness.

Limitation of the present study was women awareness of their intervention because of counseling intervention nature, thus blindness was not applicable.

\section{Conclusions}

Based on the results of the present study, it can be concluded that although both face-to-face and online methods have been able to significantly reduce the anxiety and metaworry of women with a history of miscarriage, online counseling was more effective, more sustainable, and more satisfying. Considering corona virus 19 outbreak, the importance of distance online counseling to help who needed these services is crucial. This may be due to the significant impact of online space as well as attractiveness, cost-effectiveness, the possibility of readily designing questions and dealing with concerns compared with other techniques, thus providing the ease and effectiveness of counselor-client interaction.

\section{Abbreviations}

Abbreviation was not used in this manuscript.

\section{Declarations}

\section{Ethics approval and consent to participate}


The study protocol was approved by of the ethics committee Shahid Sadoughi University of Medical Science, Yazd, Iran (Code: IR.SSU.REC.1397.091) and registered in Iranian Registry of Clinical Trials (IRCT Code: IRCT 20181120041707N1). Written informed consent was obtained from all women participating in the study.

\section{Consent for publication}

Not applicable.

\section{Availability of data and material}

The authors are not permitted to share sources of data publicity without authorization of the Vice Chancellor for Technology Research of Shahid Sadoughi University of Medical Sciences except being necessary.

\section{Competing interests}

All three authors MG, TF and $\mathrm{HZ}$ in cluding MG is a midwifery counselor, TF (as director of research) is a faculty member of Shahid Sadoughi University of Medical Sciences, and HZ is a faculty member of Psychology Department in Yazd University declare they have no competing interests.

\section{Funding}

This manuscript resulted from Msc degree thesis in Midwifery counseling. The authors thank the Vice Chancellor for Technology Research of Shahid Sadoughi University of Medical Sciences Yazd, Iran, for approving and financing the project, that they played no role in the study design, sampling and data gathering, statistic analysis of collected data and its interpretation or writing of the manuscript.

\section{Authors' contributions}

MG contributed in study design, sampling, intervention and findings interpretation of findings. TF (as director of research) selected study topic and cooperated in study design, supervised on data collection, sampling, intervention and performed data analysis and interpretation. $\mathrm{HZ}$ contributed in providing content of consulting sections and data analysis and interpretation. MG, TF and HZ participated in manuscript writing.

\section{Acknowledgements}

The authors thank the Vice Chancellor for Technology Research of Shahid Sadoughi University of Medical Sciences, Yazd, Iran for approving and financing the project as well as the women participating in the study.

\section{Author details}


${ }^{1}$ School of Nursing and Midwifery, Shahid Sadoughi University of Medical Sciences,Yazd,Iran, Bouali Ave, Safaeeyeh, Yazd, Iran. ${ }^{2}$ Research Center for Nursing and Midwifery Care, Shahid Sadoughi University of Medical Sciences, Yazd, Iran, Bouali Ave, Safaeeyeh, Yazd, Iran. ${ }^{3}$ Department of psychology, Yazd University, Yazd, Iran, Pajohesh Bolvar, Yazd, Iran.

\section{References}

1. Cunningham FG,Leveno KJ,Bloom SL, Hauth JC, Gilstrap III LC, WenstromKD. William's obstetrics. 22nd ed. New York: McGraw-Hill; 2014.

2. Burkman RT: Berek \& Novak's gynecology. JAMA 2012, 308(5):516-517.

3. Motaghi Z, Poorolajal J, Keramat A , Shariati M, Yunesian M, Masoumi SZ. Induced abortion rate in Iran: a meta-analysis. Arch Iran Med 2013; 16(10):594-8. (Full text in Persian)

4. Steinberg JR, Tschann JM, Furgerson D, Harper CC. Psychosocial factors and pre-abortion psychological health: The significance of stigma. Social Science \& Medicine J. (2016): 67-75.

5. Lok IH, Neugebauer R: Psychological morbidity following miscarriage. Best Practice Research Clinical Obstetrics Gynaecology 2007, 21(2):229-247.

6. Afzali SM, Masoudi R, Etemadifar S, Moradi M-T, Moghaddasi J: The effect of progressive muscle relaxation program (PMR) on anxiety of patients undergoing coronary heart angiography. Journal of Shahrekord Uuniversity of Medical Sciences 2009, 11(3):77-85. (Full text in Persian)

7. Othman Z: The impact of technologis and metacognition in a lifelong learning. Seminar Kebangsaan Pembelajaran Sepanjang Hayat 2014, 10.

8. Fadai F, Pourreza M, Hashemian K: omedy effect in reducing depression in schizophrenic patients. Journal of Rehabilitation 2009, 1(2):88-98. (Full text in Persian)

9. Kajbaf MB, Ghasemiannejad Jahromi A, Ahmadi Forushani SH: The effectiveness of spiritual and existential group therapy on the rates of depression, death anxiety and afterlife belief among students: a study based on the reports of people with death experience. JSR 2016, 16(4):4-13. (Full text in Persian)

10. Atter parsaei F, Ordoshahi M. complication of abortion, tabriz university of medical sciences, $2000 ; 1$ ( 19).53-93.

11. Nordahl H, Wells A: Metacognitive Therapy for Social Anxiety Disorder: An A-B Replication Series Across Social Anxiety Subtypes. Frontiers in Psychology 2018, 9:540.

12. Sattary NajafAbady R: The effectiveness of meta-cognitive treatment on test anxiety in students. Journal of Behavioral Sciences 2015, 9(1):27-32.

13. Murakami $\mathrm{H}$, Matsunaga $\mathrm{M}$, Ohira $\mathrm{H}$ : Association of serotonin transporter gene polymorphism and emotion regulation. Neuroreport 2009, 20(4):414-418.

14. Kraus R, Stricker G, Speyer C: Online counseling: A handbook for mental health professionals: Academic Press; 2010. 
15. Sule B: Technology based counseling: perspectives of Turkish counselors. Procedia - Social and Behavioral Sciences 2015, 8(1):176-431.

16. Freeman M, Schrimsher R, Kendrach M: Student perceptions of online lectures and webct in an introductory drug information course,. American journal of pharmaceutical education. 2006;70(6).70 2006, 6:1-15.

17. Cousineau T, Green T, Marianne T, Applegarth L, Davidson M, Perloe M: Online psychoeducational support for infertile women: a randomized controlled trial. Hum Reprod 2008, 23(3):554-566.

18. Wallin EEK, Mattsson S, Olsson EMG: The preference for internet-based psychological interventions by individuals without past or current use of mental health treatment delivered online: a survey study with mixed-methods analysis. JMIR mental health 2016, 3(2).

19. Lohr PA, Aiken AR, Forsyth T, Trussell J: Telephone or integrated contraception counselling before abortion: impact on method choice and receipt. BMJ Sex Reprod Health 2018, 44(2):114-121.

20. Coleman PK, Coyle CT, Rue VM: Late-term elective abortion and susceptibility to posttraumatic stress symptoms. Journal of pregnancy 2010, 2010.

21. Ranjbar F, Ashk Torab T, Dadgar A: The effectiveness of Cognitive Behavior Therapy by group method on depression.Journal of Shaheed Sadoughi University of Medical Sciences 2010, 18(4).299306. (Full text in Persian)

22. Zolfagharii H, Miri M, Mokhtarpour H: The Effectiveness of Metacognitive Therapy on Cognitive Deficits in Elderly with Substance use. Journal of Aging Psychology 2015, 1(2):11-21. (Full text in Persian)

23. Kermani H, MOZAFFARI A: The Study of Iranian Users' Reasons in Preferring Telegram on Other Instant Messaging Applications. Media studies 2018, 13(1 (40) \#b00504):7-20. (Full text in Persian)

24. Kaviani H, Mousavi AS. Psychometric properties of the Persian version of Beck Anxiety Inventory (BAI) in age \& sexualityclasses of Iranian population. Tehran Univ Med Sci 2008; 66(2): 126-40. (Full text in Persian)

25. Wells A: Emotional Disorders and Metacognition.: Innovative Cognitive Therapy: John Wiley \& Sons; 2002.

26. Sharifi Shaki S, Aakhte M, Alipor A, Fahimi Far A, Taghadosi M, Karimi R, Nadjafi M: The effectiveness of mindfulness-based cognitive therapy in reducing anxiety and meta-worry in women with recurrent miscarriages. Journal of Kashan University of Medical Sciences 2015, 19(4):334-340. (Full text in Persian)

27. Arab M, Pouragha B, Movahed Kor E, Mohammadzadeh Jamalian M: Development of an Outpatients' Satisfaction Questionnaire for Hospitals of Tehran University of Medical Science. Hakim Health 2014, 17(2):127-137. (Full text in Persian)

28. Arab M, Rashidian A, Rahimi Forushani A, Zarei E: The Effect of Service Quality on Patient loyalty: a Study of Private Hospitals in Tehran, Iran.Iranian J Publ Health 2012, 41(9):71-77. (Full text in Persian) 
29. Wells A, Fisher P, Myers S, Wheatley J, Patel T, Brewin CR. Metacognitive therapy in recurrent and persistent depression: A multiple-baseline study of a new treatment. Cognitive Therapy and Research. 2009;33(3):291-300.

30. Mahmoud Aliloo M, Abdolpour G: The effectiveness of meta-cognitive therapy on anxiety and depression in patients with posttraumatic stress disorder The Journal of Urmia University of Medical Sciences, Vol 27 (3), June 2016 2016, 27(3):222-230. (Full text in Persian)

31. Jlala H, French J, Foxall G, Hardman J, Bedforth NJBjoa: Effect of preoperative multimedia information on perioperative anxiety in patients undergoing procedures under regional anaesthesia. 2010, 104(3):369-374.

32. Kersting A, Dölemeyer R, Steinig J, Walter F, Kroker K, Baust K, et al. Brief Internet-based intervention reduces posttraumatic stress and prolonged grief in parents after the loss of a child during pregnancy: a randomized controlled trial. Psychotherapy and psychosomatics. 2013;82(6):372-81.

33. Olthuis J, Watt M, Bailey K, Hayden J, Stewart S: Therapist-supported Internet cognitive behavioural therapy for anxiety disorders in adults. Cochrane Database Syst Rev 2015, 5(3):CD011565. doi: 011510.011002/14651858.CD14011565.

34. Delaram M, Soltanpour $F$. The effect of counseling in third trimester on anxiety of nulliparous women at the time of admission for labor. Zahedan Journal of Research in Medical Sciences. 2012 1;14(2):61-5. (Full text in Persian)

35. Akhteh M, Alipor A, Sarifi Saki S: Effectiveness of Stress Management Training in Reducing Anxiety and Meta-worry of Women Who Had Abortion Several Times. Sci JManage Syst, 3(11):120-129. (Full text in Persian)

36. SalehMoghaddam A, Mazloum S, Zoka AJTJUNMF: The effect of educational videos on preoperation anxiety among patients before undergoing open heart surgerywithout pump. The $J$ Urmia Nurs Midwifery Fac 2016, 14(7):648-657. (Full text in Persian)

37. Carlbring P, Andersson G, Cuijpers P, Riper H, Hedman-Lagerlöf EJCBT: Internet-based vs. face-to-face cognitive behavior therapy for psychiatric and somatic disorders: an updated systematic review and meta-analysis. 2018, 47(1):1-18.

38. Ruffinengo C, Versino E, Renga GJEJoCN: Effectiveness of an informative video on reducing anxiety levels in patients undergoing elective coronarography: an RCT. 2009, 8(1):57-61.

39. Ghalibaf A, Karimi H, Moghadam N, Bahaadinbeigy K: Assessing satisfaction, technology usability, and therapeutic alliance in tele-psychotherapy from patients' and counselor's perspective. Journal of Health Administration (JHA) 2015, 18(61). (Full text in Persian)

40. Wells A: Metacognitive therapy for anxiety and depression: Guilford press; 2011.

41. Cicila LN, Georgia EJ, Doss BDJA, Therapy NZJoF: Incorporating Internet-based interventions into couple therapy: Available resources and recommended uses. 2014, 35(4):414-430.

42. Kermani $H$, Mozaffari A, A: The study of Iranian users' reasons in preferring Telegram on other Instant Messaging Applications. Media Studies jouna/2018, 13(40):8-21. (Full text in Persian) 
43. Mehdipour Y, Noori T, Mehraeen E, Khajepour E, Balochzehi Shahbakhsh F, Farhadi EJJoH, Informatics B: Utilization of telemental health services from the viewpoints of psychology students of Zahedan Universities. 2015, 1(2):122-130. (Full text in Persian)

44. Allen IE, Seaman J. Going the distance: Online education in the United States, 2011: ERIC; 2011.

45. Wu J-H, Tennyson RD, Hsia T-LJC, Education. A study of student satisfaction in a blended e-learning system environment. 2010;55(1):155-64.

\section{Figures}

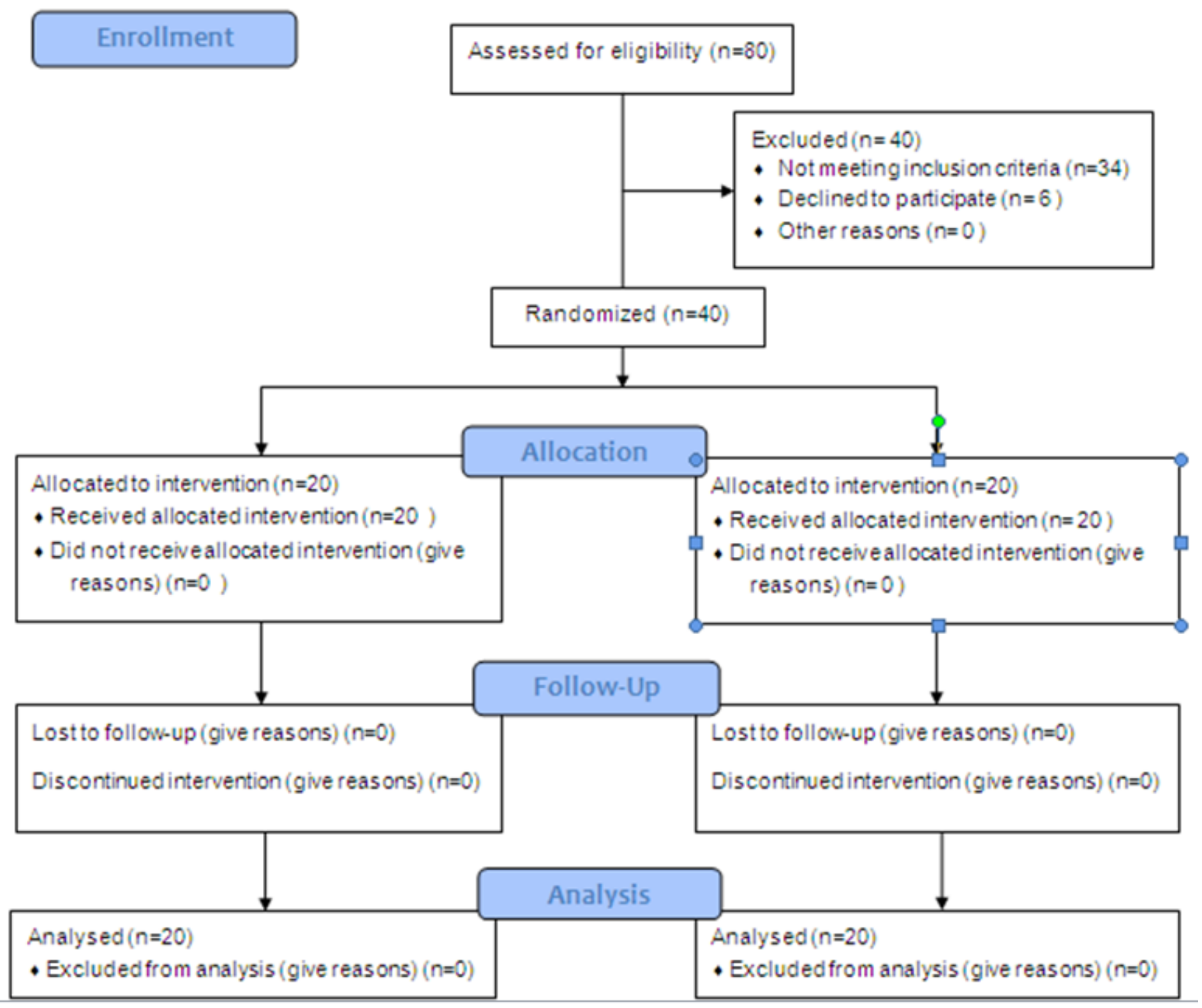

Figure 1

Diagram Consort 


\section{Supplementary Files}

This is a list of supplementary files associated with this preprint. Click to download.

- CONSORT2010Checklistfilled16.7.99.doc 